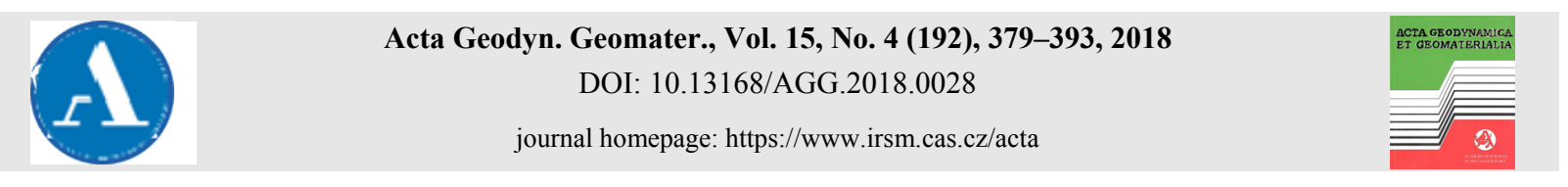

ORIGINAL PAPER

\title{
A METHOD FOR MEASURING COALBED METHANE CONTENT IN COAL STRATA WITHOUT THE LOSS OF THE GAS
}

\author{
Victor NAZIMKO \\ Department of Coal Exploitation and Mining, Institute for Physics of Mining Processes, National Academy of Sciences, 15 , \\ Simferopol St., Dnipro, 49005, Ukraine \\ *Corresponding author's e-mail victor.nazimko@gmail.com
}

\begin{abstract}
ARTICLE INFO
Article history:

Received 18 September 2018

Accepted 23 November 2018

Available online 6 December 2018

Keywords:

Coal strata

Coalbed methane

Exploration

Gas content

ABSTRACT

This paper describes an invented method for direct measurement of coalbed methane content in situ. In contrast to known procedures, this method does not need to place a rock or drilling cuts into an airtight canister, and does not involve sealing of the hole. Moreover, the new method is monitoring methane content in situ continuously and synchronously during drilling the hole not losing any portion of the gas. These positive features are a sequel of new approach based on injection of known portion of neutral gas into the hole. Methane content was determined from concentration of the mixture 'methane-neutral gas' at the hole's mouth. New method is applicable for commercial recovery application of coalbed methane and forecast of dangerous gas and coal bursts. FLAC3D computer simulation helped to investigate dynamics of methane outflow from the hole to account for the effect of drilling speed on the rate of gas emanation.
\end{abstract}

Measurement

Lost gas

Coal mine safety

\section{INTRODUCTION}

According to World Energy Council forecast, coal production grows due to steady low prices, increasing electricity demand, evolution and deployment of new clean technologies of coal combustion and the big potential reserves (World, 2016). This prediction has come true because more than seven billion metric tons of coal have been extracted annually worldwide in recent times, wherein the underground mines produce approximately one third of the hard coal. Methane content raises in coal strata as the depth increases and has enlarged up to $20 \mathrm{~m}^{3} / \mathrm{t}$ (Cheng et al., 2018; Saghafi, 2017) and even more at the deep horizons. This augmented safety concern because of gas and coal bursts, methane explosions, and underground fires.

Chronologically, the safety considerations were the primary motivations to determine the coalbed methane content in the coal strata (Kissel, 1973). Later, potential for commercial recovery application of coalbed methane and the problem of greenhouse effect created other stimuli to develop technologies for measurement the coalbed methane content. Geologists use it for calculation of gas resources to forecast gas production (Liu and Harpalani, 2014), whereas operators evaluate methane control options during underground coal mining (Zhang et al., 2016).
There are two general approaches to evaluate coalbed methane content in coal strata: indirect and direct. Indirect methods serve as a preliminary assessment tool for mine planning purposes and exploration of potential areas for commercial coalbed methane exploitation. Indirect methods may use sorption isotherm data (Kim, 1977) providing information about the storage capacity of a coal sample, but it should be measured under geological realistic pressure and temperature conditions that are a problem. A combination of wireline geophysical logging (Szabó and Dobrók, 2013) and an empirical dependence of coalbed methane content on rank of coal and depth position (Mullen, 1989) is another indirect approach for preliminary estimation of methane resources. Recently new approaches such as seismic methods (Ali et al., 2018) began to gain popularity for indirect assessments of gas content in coal bearing strata. However all indirect methods can predict potential amount of methane in coal bearing strata as a first approximation.

The direct methods of methane content measurements attracted more attention because they are more accurate and reliable and are widely accepted in USA (Diamond and Levine, 1981), Australia (Standards, 1991; Black, 2017), China (Cheng et al., 2017), Poland (Szlązak and Korzec, 
2016) and other countries, which intensively exploit coal deposits. The direct methods use a fresh core or drilling cuttings from underground drill holes. Investigators place these coal samples into airtight canister and transport them in a laboratory. Methane content may be recorded using so called extended desorption gas content measurement techniques (Diamond and Levine, 1981), when process of gas emanation from the core is monitored until a cutoff point of low desorption rate is reached. The extended techniques may last for months if tested coal is blocky and has low permeability. Consequently, the tested core may be crushed to a powder that activates desorption of residual gas (Saghafi, 2017).

So called "quick"-crushing techniques allow test both desorbed and residual gas in a matter of days due to crashing fresh core immediately after delivering it in a laboratory. Investigators use the residual gas content in a basic fundamental research that has not gained essential practical implementation so far. Bertard et al. (1970) and Levine (1992) pointed out that the residual methane represents the gas that did not desorb from a sample under atmospheric pressure and at least partly could emanate in vacuum.

Bertard et al. (1970) were the first who found two stages of methane desorption, namely quick and slow. Rate of the gas desorption was proportional to the square root of time during the quick stage of desorption that occurs immediately after a hole drilling. Later, process of gas emanation decays and may be described with logarithmic law. Quick release of the gas at the early stage indicates that process of filtration of the free gas prevails, whereas slow rate of subsequent desorption depends on release of deeper layers of adsorbed and absorbed molecules of methane. Duration of the earlier stage is in diapason of several minutes what coincides with period of the catastrophic dynamic events during gas and coal or sandstone bursts. Therefore, quick methane plays decisive role in development of the bursts, although it escapes from the measurement.

Unfortunately, all used in practice direct methods fail to register the quick gas, which releases at the early stage. Bertard et al. (1970) assessed amount of the lost gas up to $20 \%$ of the total gas, Rightmire (1984) testified from $5 \%$ to $17 \%$, whereas Szlązak and Korzec (2016) stated $12 \%$. Guiyang et al. (2017) reported that they reduced error of standard direct method to $10 \%$ relatively an error provided by an indirect method. Although the absolute error remained uncertain, because they expanded the sampling time to $30 \mathrm{~min}$ and did not account the quick (free) gas.

A possible share of the lost gas may depend on permeability of the coal sample. Variance of the lost gas volume is also a sequel of different period between recovering coal sample from the hole and placing it into airtight canister. This period depends on subjective skill of operators and cannot be determined accurately. In addition, Kissell et al.
(1973) considered that process of desorption starts from the moment of sample penetration with a boring instrument. However great pressure gradient existing in front of the hole's face causes intensive desorption of the gas ahead of the penetration front. Therefore, amount of the lost gas may be underestimated. Noteworthy, assessment of the lost gas volume may be done with extrapolation only, which adds extra uncertainty. That is why Ryan and Dawson (1993) concluded, "There is no foolproof way of making lostgas corrections" (p. 255).

A discrete nature of existent direct methods is another weakness, because operators collect samples in separate points of a borehole. It causes another uncertainty as the variation of gas content in the different points of the rock mass may occur either because of a natural deviation or as a consequence of measurement error.

Owen and Sharer (1992) proposed to eliminate losing of the free gas using pressure coring. However, this method was not put into practice because high cost of this procedure and complexity of technical implementation.

Another standard method of coalbed methane content measurement is in use in the countries of former USSR (Ukraine, Russia, Kazakhstan) (Regulations, 2005). This method directly monitors so- called initial rate of methane emission from the $0.5 \mathrm{~m}$ advancing section of a borehole that is periodically sealed with a special mechanical packer. This packer should be installed in the hole no later than $120 \mathrm{sec}$ after drilling every next $1.0 \mathrm{~m}$ interval. According to this standard procedure, operators should manage to take out the drilling bar from the hole and insert the packer having a differential pressure gage (flow meter) during this period. However, this method has the same disadvantage, as certain volume of the quick gas is lost due to this operation because of the pause between drilling and measurement as well as poor-quality mechanical insulation of the hole that stimulates extra losing of the gas. In addition, the pause is increasing as the hole becomes deeper. Nevertheless, testing of the gas desorption rate in situ thermodynamic condition is an advantage.

Modern continuous miners provide from 5 to 10-meter advance per hour during panel development, and their retreat rate of $500 \mathrm{~m}$ per month is widely accepted. Such intensive coal extraction raises probability of gas and coal bursts and bumps. These high rates of panels' development and longwalls' movement need for prompt evaluation of coalbed methane content, whereas existent direct methods are excessively time consuming. This is especially critical where methane content varies in space and, specifically, around geologic micro-faults that are origins of gas bursts and are usually abandoned in coal deposits.

Development of unconventional resources of coalbed methane needs for underground mining, 


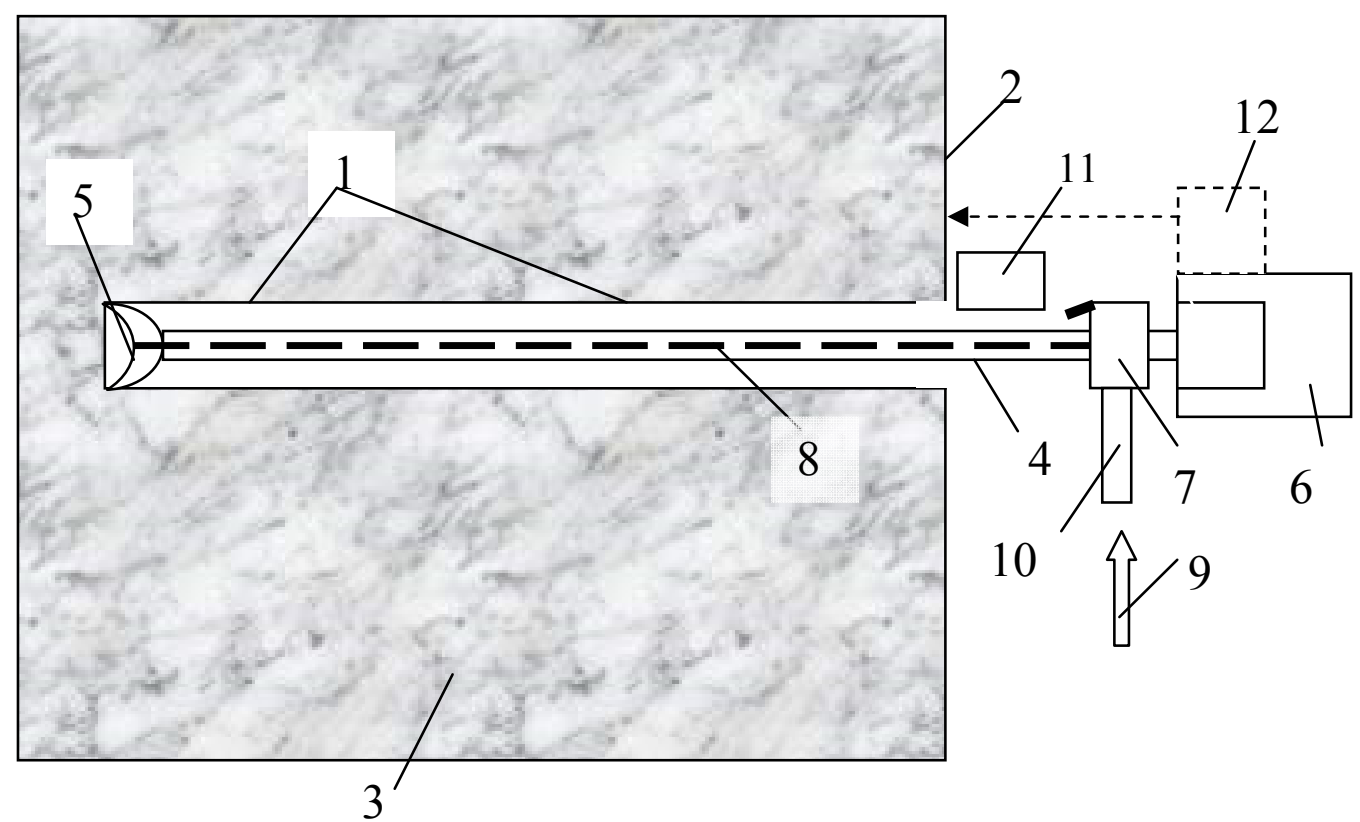

Fig. 1 Measuring when drilling system: 1 - hole; 2 - coal exposure; 3 - coal seam; 4 - drilling rod; 5 - bit; 6 - motor; 7 - obturator; 8 - channel; 9 - neutral gas; 10 - flow meter; 11 - device for measuring methane concentration; 12 - laser distance meter

because longwall technology provides favorable conditions for methane filtration due to dramatic increase in permeability after undermining and fracturing of coal bearing strata. On one hand, the more coalbed methane content, the more efficient and profitable exploitation of this resource becomes. On the other hand, high content of the gas that is able both to explode and to burst restricts the rate of panels' development and their extraction, what controverts economic demands. Therefore, geologists as well as operators should measure coalbed methane content quickly and with ultimate accuracy and reliability to predict the danger of dynamic manifestation of the gas as well as to control and test anti-burst preventive measures. Direct monitoring of the free quick coalbed methane will provide such demand. This paper describes a pioneering method for continuous measuring.

\section{DEVELOPMENT OF A NEW METHOD FOR DIRECT CONTINUOUS MEASUREMENT OF COALBED METHANE CONTENT IN COAL STRATA WITHOUT THE LOSS OF THE GAS.}

Catching of all methane including the free quick gas may be achieved by changing of measurement principle that should remove the pause between the drilling and the measuring processes. In addition, continuous monitoring of methane content synchronously to the drilling would enhance both accuracy of the gas content determination and desorption dynamics registration. A new method based on these principles has been described in the next paragraph.

\subsection{DESCRIPTION OF NEW METHOD}

Invented method (Nazimko and Roy, 2018) of direct measurement of coalbed methane from a borehole needs not to recover a coal sample or seal the hole and does not lose the gas. All desorbing methane is monitored continuously and synchronously during drilling a hole. Let me call this method as a method of methane content synchronous measurement during drilling a hole or MCSM for short. Figure 1 demonstrates schematic of the method. An operator drills the hole 1 from the exposure 2 of a coal seam 3 using drilling rod 4 , bit 5 , and motor 6 . Obturator 7 is installed on the drilling rod 4 having a channel 8 . This obturator is immovable when the drilling rod is rotating. Inert neutral gas 9 (fresh air, nitrogen, carbon dioxide) is injected through obturator 7 and channel 8 into hole 1. Methane and neutral gas mix properly due to turbulent movement of the mixture from the hole's face to the hole's mouth. Flow meter 10 monitors the rate of the introduced inert gas 9 , which dilutes the methane in advancing section of the hole 1. Mixture of methane and inert gas moves to the outlet of the hole 1 , where device 11 records concentration of the methane. Laser distance meter 12 monitors current depth of the hole 1. Figure 2 shows overall view of the drilling equipment.

Concentration of the methane $C_{g}$ is:

$C_{g}=\frac{V_{g}}{V_{g}+V_{a}} 100, \%$

Where $V_{g}$ is rate of methane outflow from the hole (volume per time) and $V_{a}$ is rate of the neutral gas 


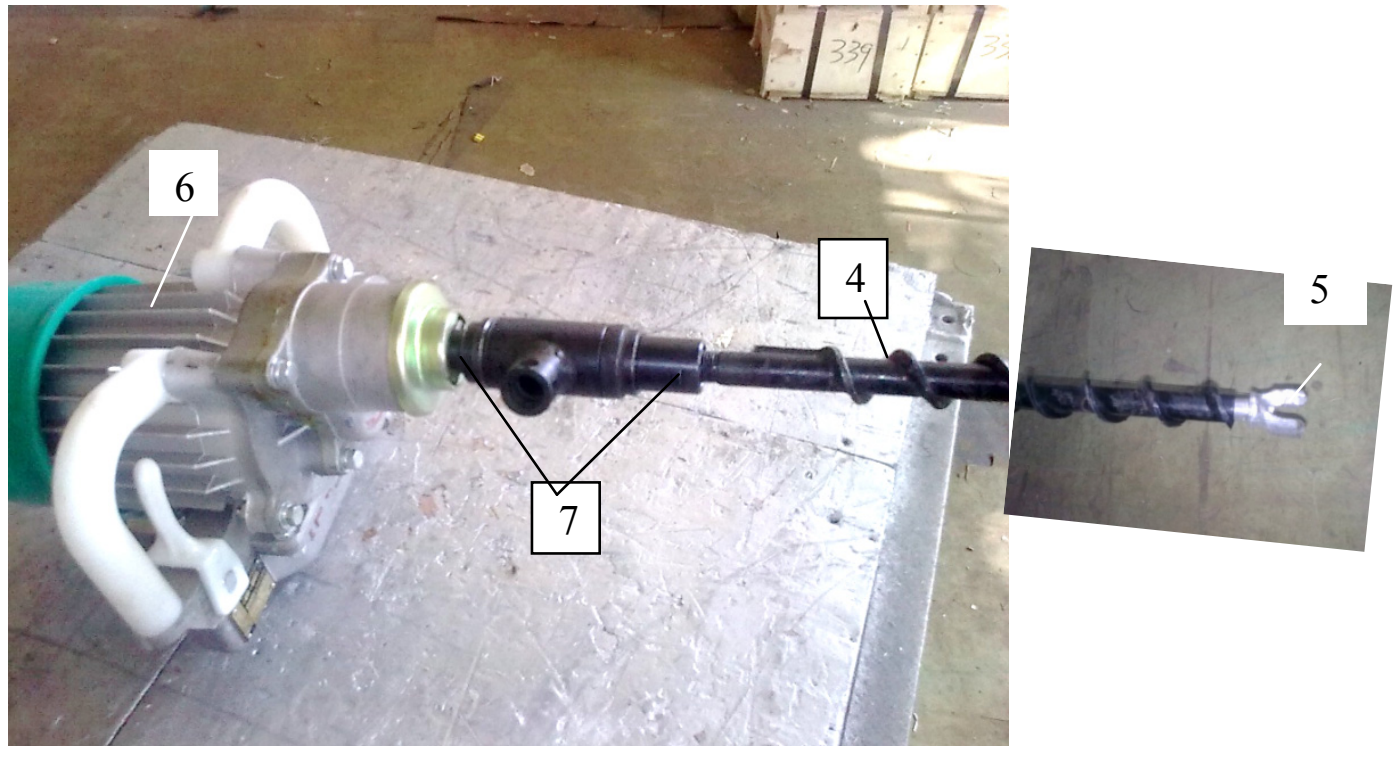

Fig. 2 View of the drill: list of items is the same as in Figure 1.
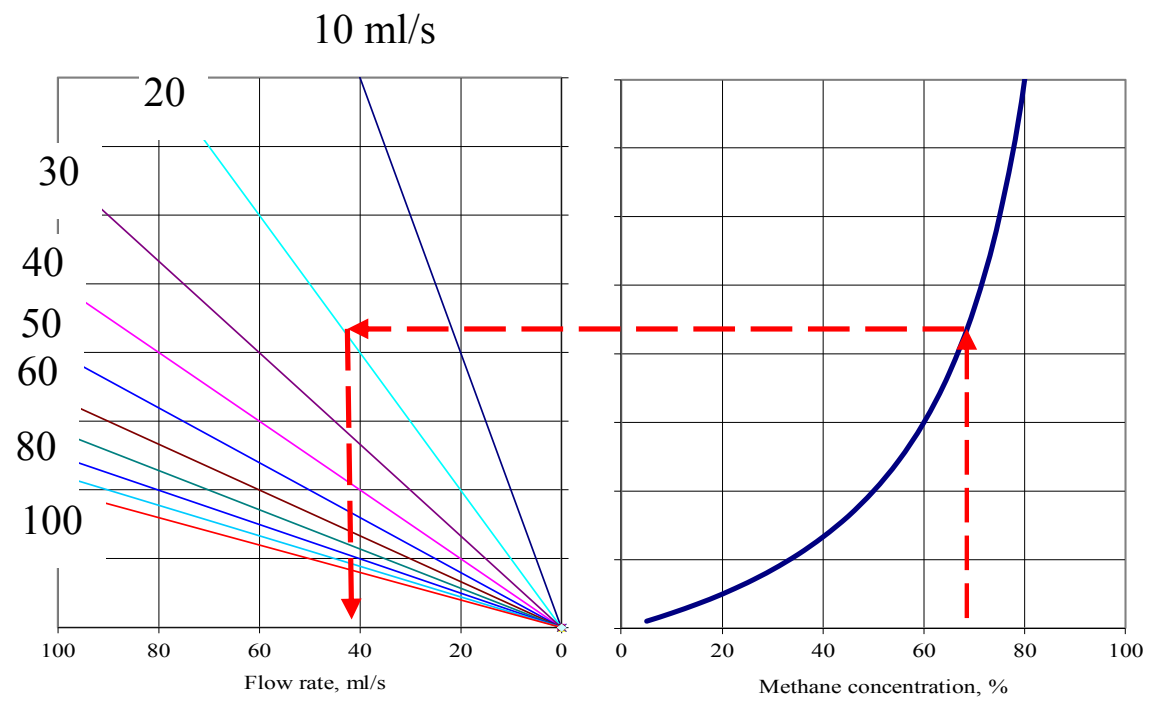

Fig. 3 Diagram explaining principle of methane content determination.

injection. Therefore, current rate of methane outflow can be determined according formula:

$$
V_{g}=\frac{C_{g} V_{a}}{\left(100-C_{g}\right)}
$$

Figure 3 depicts nomogram for simple determination of gas desorption rate that is a function of the mixture concentration $C_{g}$ and the rate of the neutral gas injection $V_{a}$. Possible rates of added neutral gas are indicated in milliliters per second for the case when a hole has diameter of $40 \mathrm{~mm}$. For example, fresh air injected with the rate of $20 \mathrm{ml} / \mathrm{s}$ diluted methane to concentration $68 \%$. Therefore, the rate of methane outflow was $42 \mathrm{ml} / \mathrm{s}$ in the case.

\subsection{TESTING OF MCSM METHOD IN UNDERGROUND COALMINE}

MCSM method has been tested in Krasnolimanska coal mine, Ukraine. Coal seam $1_{8}$ was extracted by $7^{\text {th }}$ north longwall at the depth of $845 \mathrm{~m}$. Thickness of the seam was $1.65 \mathrm{~m}$. Immediate roof was presented with $3.4 \mathrm{~m}$ shale covered with $5.1 \mathrm{~m}$ sandy shale whereas $2.8 \mathrm{~m}$ grey shale represented immediate floor of the coal seam. A head entry developed $7^{\text {th }}$ north panel with underground road header CSP60. Average rate of advance of the head entry was $210 \mathrm{~m} / \mathrm{month}$. According to experience of mining in adjacent panels, preliminary assessment of average coalbed methane content was $10.4 \mathrm{~m}^{3} / \mathrm{t}$ at the $7^{\text {th }}$ north panel area. However, geology of the seam was complex and unstable due to thickness variation. In addition, geologists predicted several micro-faults 
at the area of this panel, and the seam was prone to gas and coal bursts. Therefore, periodic control of coalbed methane content was the mandatory procedure according to the safety regulations.

A research group $(R G)$ joined a special team of coal burst forecast (TBF) and measured gas content twice. The first time (experiment $\# 1$ ) the face degassed because the head entry has stopped as the road header has malfunctioned for 2 days. The second time (experiment \#2) we measured gas content immediately after the road header advanced the entry to $1 \mathrm{~m}$. TBF drilled two parallel holes on the face and measured gas content in one of them using standard method, while RG measured methane outflow in the other hole with MCSM method. TBF used packer PS1 to seal the $0.5 \mathrm{~m}$ advancing section of the hole and differential manometer PG-2MA to measure rate of methane outflow from the sealed section. Standard error of methane flow registration was $\pm 5 \%$. RG used fresh air as the neutral gas and monitored its flow with rotameter EMIS-META 215 (050B) having standard error of $\pm 2.5 \%$. Concentration of the mixture of the methane and fresh air was measured with chromatograph SI-12 providing diapason of measured concentration from 0 to $100 \%$ and standard error of $\pm 0.4 \%$.

Distance between the holes was $2.0 \mathrm{~m}$ and gas content has been measured at the depth of $2.0 \mathrm{~m}$. This prevented reciprocal influence of the holes on the gas pressure in situ while provided identical conditions for the experiments. In the first experiment, TBF inserted packer and sealed the $0.5 \mathrm{~m}$ advancing section of the borehole $94 \mathrm{sec}$ after drill bit had penetrated the last portion of the coal seam at the depth of $2.0 \mathrm{~m}$. RG monitored rate of methane outflow continuously during drilling of the experimental hole. The rate of gas outflow depends on the speed of a hole's face advance regardless which method of measurement to use. However, standard methods do not account for the rate of hole's drilling whereas MCSM method is highly sensitive to this factor. Therefore, RG measured rate of the gas discharge at the end of drilling process trying to keep the rate of hole's face advance at $2 \mathrm{~cm} / \mathrm{s}$. Such pace was comfortable for operator who kept and controlled the drill. TBF registered no gas in the hole, whereas $R G$ measured rate of methane discharge at the minimal level of $0.011 \mathrm{dm}^{3} / \mathrm{s}$.

During the second experiment, TBF managed to insert the packer into the hole $72 \mathrm{sec}$ after stopping the drilling and registered $1.2 \mathrm{dm}^{3} / \mathrm{min}$ of methane discharge that was less than critical amount of 4.0 $\mathrm{dm}^{3} / \mathrm{min}$ for this geologic condition according to (Regulation, 2005). It means the situation was not dangerous and gas burst was impossible. MCSM method registered rate of the gas outflow of 0.135 $\mathrm{dm}^{3} / \mathrm{s}$ or $8.1 \mathrm{dm}^{3} / \mathrm{min}$. However, it is impossible to compare these values directly because standard method accounted the desorbing gas (excluding lost methane) from restricted section of the hole having limited length of $0.5 \mathrm{~m}$, whereas the MCSM method registered all gas from the entire hole's cavity not losing any portion of the gas. The deeper the hole penetrates a coal seam the more surface of coal exposure expands inside the hole that should be resulted in raising both rate of the gas desorption and total discharge volume. In addition, gas content should also increase during transition from the face of an entry, where gas pressure is at atmospheric level, into deep space of coal seam, where pore pressure is maximal and corresponds to in situ pressure level. Therefore special analysis should be conducted to investigate process of methane discharge from the hole taking into consideration rate of drilling and depth of the borehole.

\subsection{ASSESSMENT OF ACCURACY OF THE GAS CONTENT MEASUREMENT}

Methane desorption and neutral gas injection is independent processes, thus standard deviation of the $V_{g}$ may be expressed as:

$m^{2}=\sigma_{c}^{2} \cdot \partial f / \partial C_{g}+\sigma_{a}^{2} \cdot \partial f / \partial V_{a}$

where $m$ is standard deviation of methane outflow determination;

$\sigma_{c}$ and $\sigma_{a}$ are standard errors of methane concentration and neutral gas injection measurement;

$f$ is the function that expressed by equation (2).

Table 1 demonstrates the results of partial derivations calculation and standard error, which characterizes determination of methane outflow giving $\sigma_{c}=0.4 \%, \sigma_{a}=2.5 \%$, and $V_{a}=4$ liter per minute or $66.7 \mathrm{ml} / \mathrm{s}$, that is the critical level of methane outflow for outburst prediction according (Regulations, 2005). This critical value is relevant for the hole having $40 \mathrm{~mm}$ diameter.

Variation of methane concentration in a wide diapason from 9 up to $55 \%$ keeps error of measurements in limits of $5 \%$ (Fig. 4) and minimal error is $1.65 \mathrm{ml} / \mathrm{s}$ or $2.5 \%$.

\section{COMPUTER SIMULATION OF GAS DISCHARGE FROM THE DRILLING HOLE \\ 3.1. METHODOLOGY OF SIMULATION}

TBF drills borehole from a face of a real underground roadway that is in process of driving. Both driving and drilling processes disturb static stress state around the roadway that might cause damage of surrounding rock mass involving redistribution of permeability in vicinity of the roadway. Therefore, process of methane filtration into the hole's cavity and roadway room is unsteady, and boundary conditions are mobile. Thus, a model should take into account the combined processes of ground movement, deformation, and damage as well as nonstationary filtration of methane under mobile boundary conditions (Jiang and Yang, 2018). It is evident that gas filtration process depends both on rate 
Table 1 Results of standard error calculation.

\begin{tabular}{|c|c|c|c|c|c|}
\hline$V_{a}$ & $C_{g}$ & $V_{a} \cdot \partial V_{g} / \partial C_{g}$ & $\partial V_{g} / \partial V_{a}$ & Error, $\mathrm{ml} / \mathrm{s}$ & Standard error \\
\hline 3266.7 & 2 & 34.01 & 0.02 & 13.61 & 0.204 \\
\hline 1266.7 & 5 & 14.04 & 0.05 & 5.62 & 0.084 \\
\hline 674.1 & 9.0 & 8.14 & 0.10 & 3.27 & 0.049 \\
\hline 600.0 & 10 & 7.41 & 0.11 & 2.98 & 0.045 \\
\hline 377.8 & 15 & 5.23 & 0.18 & 2.14 & 0.032 \\
\hline 266.7 & 20 & 4.17 & 0.25 & 1.78 & 0.027 \\
\hline 200.0 & 25 & 3.56 & 0.33 & 1.65 & 0.025 \\
\hline 155.6 & 30 & 3.17 & 0.43 & 1.66 & 0.025 \\
\hline 123.8 & 35 & 2.93 & 0.54 & 1.78 & 0.027 \\
\hline 100.0 & 40 & 2.78 & 0.67 & 2.00 & 0.030 \\
\hline 81.5 & 45 & 2.69 & 0.82 & 2.31 & 0.035 \\
\hline 66.7 & 50 & 2.67 & 1.00 & 2.72 & 0.041 \\
\hline 54.5 & 55 & 2.69 & 1.22 & 3.24 & 0.049 \\
\hline 44.4 & 60 & 2.78 & 1.50 & 3.91 & 0.059 \\
\hline 35.9 & 65 & 2.93 & 1.86 & 4.79 & 0.072 \\
\hline 28.6 & 70 & 3.17 & 2.33 & 5.97 & 0.090 \\
\hline 22.2 & 75 & 3.56 & 3.00 & 7.63 & 0.115 \\
\hline 16.7 & 80 & 4.17 & 4.00 & 10.14 & 0.152 \\
\hline 11.8 & 85 & 5.23 & 5.67 & 14.32 & 0.215 \\
\hline 7.4 & 90 & 7.41 & 9.00 & 22.69 & 0.340 \\
\hline 3.5 & 95 & 14.04 & 19.00 & 47.83 & 0.717 \\
\hline
\end{tabular}

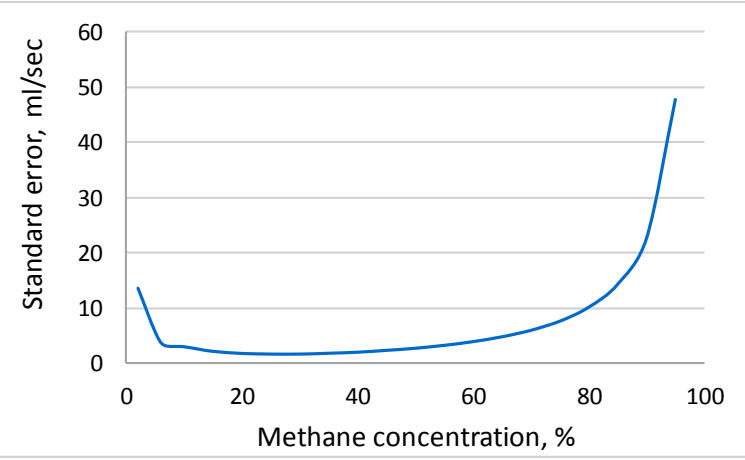

Fig. 4 Dependence of standard error of methane content on its concentration in the mixture methane - neutral gas.

of the roadway driving and on speed of drilling of the borehole.

FLAC3D (Itasca, 2008) is a relevant computer model that satisfies these conditions. FLAC3D solves a set of differential equations including the second law of Newton and constitutive equations of a plastic material behavior using the finite difference method. The program uses incremental time iterations to reach a static equilibrium or steady plastic flow of a rock mass. The same iterative algorithm is involved to solve a set of differential equations including transport (Darcy's) law, balance and constitutive laws for finding steady state of a liquid or transitive flow in a rock mass as a porous media. Iterations continue until unbalanced mechanical forces in a model become negligible or gas flows in grid nodes become steady.

Noticeably, holes are drilled from the coalfaces of underground openings that are usually moving with remarkable speed, for example $10 \mathrm{~m}$ per day and more. Therefore, neither mechanic stress in the ground nor gas pressure in vicinity the moving face is not in equilibrium. Furthermore, advance of the hole's face is much quicker during drilling, thus unstable gas pressure relief may evolve intensively around the hole. Control of iterative steps number is a relevant option to simulate these unsteady mechanical and aerodynamic processes (Nazimko and Babenko, 2011). Usually, number of the steps is chosen such as the ratio of maximum unbalance force magnitude in a model to the average applied force was less than certain limit, for example $1 \cdot 10^{-5}$. However, mechanic forces are actually unbalanced in the surrounding rock mass and gas flows are unsteady during drilling of the hole as well as driving of underground opening. Therefore, the number of iterative steps should be reversely proportional to the rate of driving and speed of drilling during mechanic simulation and fluid computation.

Figure 5 depicts a numerical model of the rock mass that was used to simulate the coupled processes of ground pressure distribution, ground movement and deformation as well as methane filtration. An octahedron having dimensions along $\mathrm{X}, \mathrm{Y}$ and $\mathrm{Z}$-axis respectively 30,32 and $60 \mathrm{~m}$ represented a block of the rock mass. A horizontal roadway has been driven along Y-axis positive direction from X0Z boundary through a horizontal coal seam having $2.8 \mathrm{~m}$ thickness. The roadway had arched shape of $2.8 \mathrm{~m}$ high and $5 \mathrm{~m}$ width. A right section of the roadway was considered because symmetry. Exploded view in Figure 5 demonstrates the hole drilled from the face of the roadway. Proper zonal discretization of the model provided reliable simulation of the gas filtration around the underground opening because size of the 


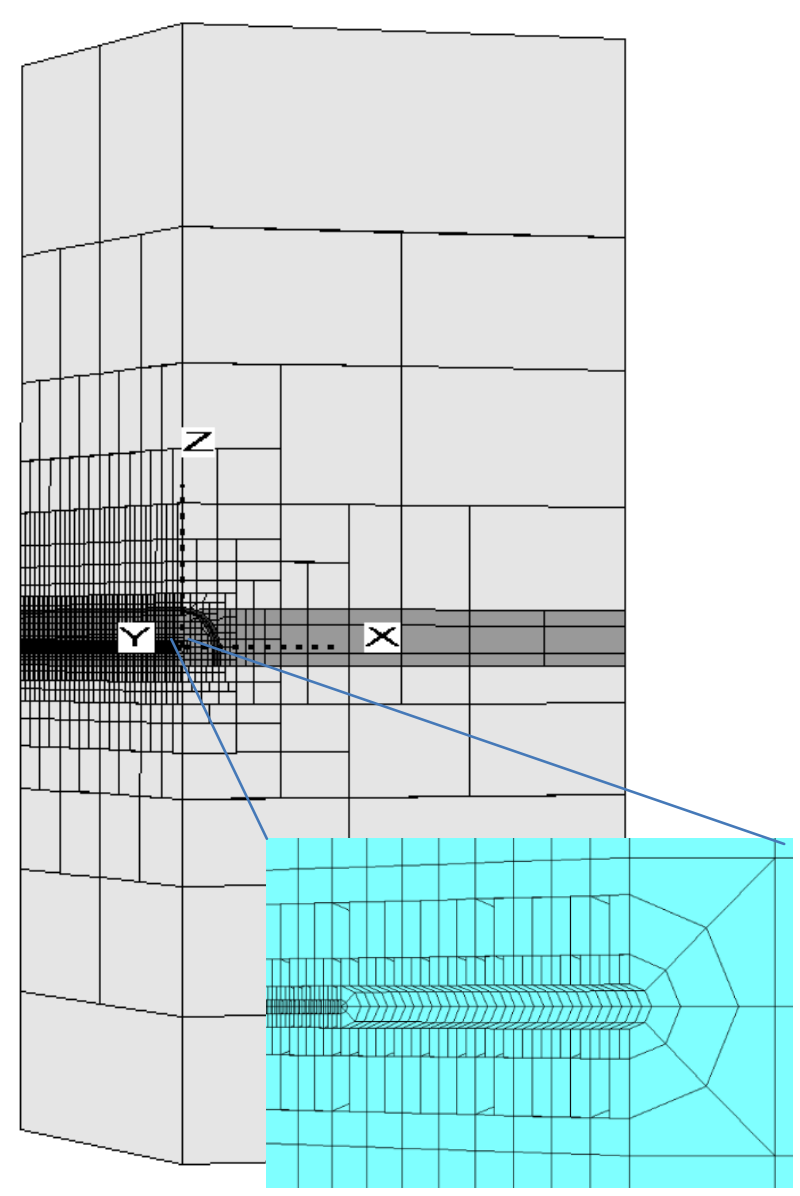

Fig. 5 FLAC3D grid for rock mass.

Table 2 Properties of the surrounding rocks.

\begin{tabular}{lllllllll}
\hline Rock type & $\begin{array}{l}\text { Bulk } \\
\text { modulus, } \\
\mathrm{GPa}\end{array}$ & $\begin{array}{l}\text { Shear } \\
\text { modulus, } \\
\mathrm{GPa}\end{array}$ & $\begin{array}{l}\text { Cohesion, } \\
\mathrm{MPa}\end{array}$ & $\begin{array}{l}\text { Angle of } \\
\text { friction, } \\
\text { degree }\end{array}$ & $\begin{array}{l}\text { Tension } \\
\text { limit, } \\
\mathrm{MPa}\end{array}$ & $\begin{array}{l}\text { Dilation } \\
\text { angle, } \\
\text { degree }\end{array}$ & $\begin{array}{l}\text { Porosity } \\
\begin{array}{l}\text { Perme- } \\
\text { ability, } \\
\mathrm{m}^{2}\end{array}\end{array}$ \\
\hline Rock & 8 & 4 & 33.6 & 32 & 3.8 & 7 & 0.001 & $2 \cdot 10^{-12}$ \\
Coal & 8 & 4 & 10.2 & 35 & 1.2 & 7 & 0.002 & $4 \cdot 10^{-12}$ \\
Lining & 8 & 4 & 12.2 & 30 & 2.9 & 7 & 0.002 & $4 \cdot 10^{-12}$ \\
\hline
\end{tabular}

zones was conversely proportional to gas pressure gradient expected. Sequential excavation of the roadway by steps of $1 \mathrm{~m}$ and drilling of the hole by steps of 0.0625 to $0.125 \mathrm{~m}$ facilitated further enhancement of the simulation process as recommended Zheng et al. (2016).

Normal displacements were restricted on the vertical boundaries of the rock mass model whereas bottom boundary was fixed. Proportional to the depth of mining ground pressure has been applied to the top of the model. Arched steel frames supported the roadway during driving. Distance between centers of the adjacent frames was $1 \mathrm{~m}$ and the closest frame lagged behind the roadway face by $1 \mathrm{~m}$. Concrete lining filled a gap between the frames and rock or coal exposure. Mechanical and aerodynamic properties of the rocks are depicted in Table 2. Initial pressure of the gas was 3.2 MPa.

Beam structural elements simulated steel frames having modulus elasticity of $200 \mathrm{GPa}$, Poisson ratio 0.30 , cross area $34 \cdot 10^{-4} \mathrm{~m}^{2}$, second moment with respect to local $\mathrm{y}$-axis $14 \cdot 10^{-6} \mathrm{~m}^{4}$, second moment with respect to local z-axis $7.31 \cdot 10^{-6} \mathrm{~m}^{4}$, and polar moment of inertia $6.46 \cdot 10^{-6} \mathrm{~m}^{4}$. Mohr-Coulomb constitutive law controlled transition of surrounding roadway rocks and coal over shear or tension limits.

Process of a gas filtration through a rock mass is highly nonlinear because its permeability depends on several factors (Zhang et al., 2018; Konečný and Kožušníková, 2016). It is widely acknowledged (Baiquan and Yang, 2017) that permeability of the coal mass increases due to degassing of methane as 


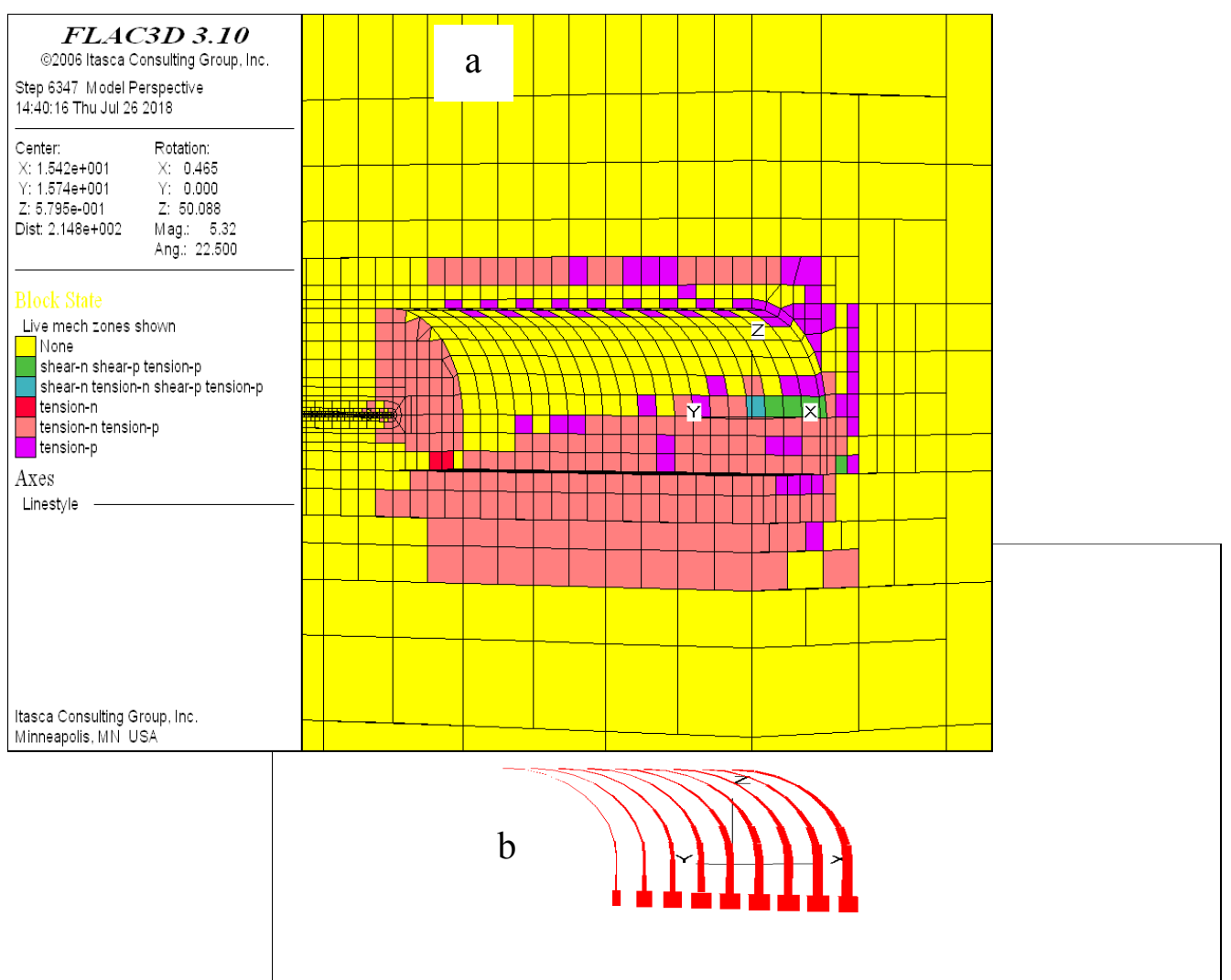

Fig. 6 Damaged zones around the roadway (a) and loading of frame support (b).

swelling of the coal abates and micro-pores increase their volume. However, fracture apertures affect permeability of a rock mass much more intensively. Zhang (2016) found that permeability increases not only after fractures' development but because they evolve an interconnection. He proposed to correct permeability as a function of the minor principal stress and volumetric strain increment:

$k=k_{0} \exp \left(-\gamma \sigma_{3}\right)\left[1-\exp \left(-\Delta \varepsilon_{D} / \varepsilon_{p}\right)\right]$,

Where $k$ is the permeability of fractured rock mass; $k_{0}$ is the permeability at the minor principal stress $\sigma_{3}=0$, and parameter $\gamma$ characterizes dilatability of inter-connected fractures. So called percolation threshold $\varepsilon_{p}$ corresponds to minimal plastic deformation that induces abrupt increase of filtration as a result of adjacent cracks' connection, and $\varepsilon_{D}$ indicates volumetric strain increment over the threshold. According to Zhang (2016), $k_{0}=3 \times 10^{-13} \mathrm{~m}^{2}$ and $\gamma=1.9 \mathrm{MPa}^{-1}$. FLAC3D calculates volumetric strain increment that provided correction of rock and coal permeability, which surround roadway and hole, destroyed, and transited over strength limits.

\subsection{MECHANICAL BEHAVIOR OF THE ROCK MASS AROUND THE DRIVING ROADWAY}

Drilling of explorative wells and holes occurs from the earth surface, high walls of the open-cut mines, or underground opening that creates specific boundary conditions. Coalbed methane content generally increases, as a mining becomes deeper (Liu and Mitri, 2007). That is why geologists monitor content of the gas from the hole and wells drilled from the underground roadways because it is the most reliable, economic, and widely accepted method for direct exploration of coalbed methane content.

To provide relevant boundary condition, roadway should penetrate the model at least to depth ranged from 1 to 1.5 times the width of the roadway. Figure 6 illustrates distribution of damaged rock and coal around the roadway at the depth of $845 \mathrm{~m}$ after the face withdrawal from the X0Z boundary to $10 \mathrm{~m}$ or two widths of the opening that, on one hand, provides confident absence of interaction between mechanical stress and gas pressure states around the model boundary and the roadway face. On the other hand, remained $20 \mathrm{~m}$ body of the model provides an opportunity to investigate the gas pressure redistribution around the drilling hole. The hole should not approach the opposite boundary $(\mathrm{Y}=32 \mathrm{~m})$ closer than its five diameters. Giving the maximum diameter of the hole of $200 \mathrm{~mm}$, the model could investigate the gas pressure and flows around the hole having length up to $19 \mathrm{~m}$.

The floor of the roadway damaged the most intensively during advance of the roadway face into the model. Majority of the surrounding rock mass 
broke because tensile stress extended to the limit of tensile strength. There are right angles on vertical section of the roadway at the flat floor. Relatively sharp angles are sources of stress concentration, and flat shape of the floor is relatively unstable. Those factors provided favorable conditions for damaged zone development to the depth of $1.5 \mathrm{~m}$ into the floor.

An arched-like roof of the roadway was more stable than the floor and damaged slightly during bending of delaminating rock layers. Sidewalls were creeping and sloughing as the face advanced. Not only tensile but shear critical stress evolved in process of sidewalls destruction during the face moving away from the model boundary. Upper part of the face transited over the strength limit and heaved into roadway cavity; thereupon central part demonstrated maximal displacement as it was the most distant from the peripheral area of the face.

Figure 6 a shows process of surrounding rock mass destruction that accompanied with steel frames loading, especially their props. Ground pressure increased the loads as damaged zone developed around the roadway and roof, sidewalls, and floor displacements accumulated. Noticeably, there was not any destruction of the rock mass around the roadway when it has been simulated at the depth of $400 \mathrm{~m}$. Anyway irreversible process of ground deformation at the big depth invested into increase of permeability of surrounding rocks according to formula (4) that augmented rate of methane desorption and filtration.

\subsection{ANALYSIS OF GAS PRESSURE REDISTRIBUTION}

Figure 7 demonstrates complex interaction between speed of driving of the roadway, rate of drilling of the hole, and gas dynamics around the openings. Maximum depth of the hole was $12 \mathrm{~m}$ here. Time scale for filtration process is an order of magnitude greater than for the mechanical behavior of the model (FLAC3D, 2008). Therefore, it is impossible to simulate very long processes of the gas filtration, in the case no longer than several hours. Nevertheless, there is a proper correlation between drilling duration and filtration period. Fragment (a) in Figure 7 demonstrates pressure distribution for the 'fast' case when speed of driving of the roadway was high (by order $40 \mathrm{~m} /$ day) and rate of hole's drilling was by order $1 \mathrm{~km} /$ day. Evidently, filtration of the gas around the roadway is independent of gas emanation around the hole. Thus, the fast case is relatively simple and presents opportunity to investigate process of filtration around the hole independently.

Figure $7 \mathrm{c}$ shows pressure distribution for 'sluggish' case when there were lower limits of driving and drilling rates (approximately $5 \mathrm{~m} /$ day driving and $1 \mathrm{~cm} / \mathrm{s}$ drilling). Pressure distribution indicates that process of the gas desorption around the roadway followed closely pressure relief in vicinity of the hole. The sluggish case is ambiguous because methane filtrations around the roadway face and in vicinity of the hole interact. It is hard to separate combined processes and study gas dynamics, however such situation occurs inevitably at the start of the hole's drilling when it goes through a drained zone. Vectors of gas flow demonstrate (Fig. 7b) there are intensive gas torrents that are normal to the hole's face immediately near the face. Therefore, methane at least partly exhausted both in front of the moving roadway and hole's face regardless the speed of their movement.

Let me compare numerical methane pressure distribution and those registered in situ (Lidin et al., 1968). Experimental monitoring of gas pressure and flow was made in Pechora coal region at the depth of $400 \mathrm{~m}$. Average content of methane in the coal deposit was $10.4 \mathrm{~m}^{3} / \mathrm{t}$. Wells having diameter $120 \mathrm{~mm}$ have been drilled from a roadway through a coal seam n14' to the depth of $50 \mathrm{~m}$. Positions of the holes are indicated along $\mathrm{X}$-axis of the diagram in Figure $8 \mathrm{a}$.

Central well (light circle) has position $(0 ; 0)$ and was assigned for the measurement of gas outflow. The other five wells (filled circles) were drilled at the distance $3.5,7.0,10.5,14.0$, and $17.5 \mathrm{~m}$ from the central well respectively. Those five wells were sealed to the length of $20 \mathrm{~m}$ and were designed for gas pressure measurement.

Five sets of points correspond to pressure distribution at certain time intervals, namely 50, 75, 100,125 , and 150 days after drilling of the experimental wells. According to these measurements, average pressure of methane in situ was 32 bar, and gas pressure distributions can be described by convex (for example logarithmic) function. Boundary of degassing zone around the central hole expanded from $6 \mathrm{~m}$ for 50 day after the well drilling up to $20 \mathrm{~m}$ after 150 day respectively. As mentioned above, FLA3D cannot simulate such a prolonged process. Thus curves on the diagram in Figure $8 \mathrm{~b}$ corresponds to $0.24,0.72,1.62,3.35$, and 6.06 hours after driving the hole. Therefore, results of computer simulation depicted in Figure 8b should be located to the left of the experimental curves. Indeed, the set of numerical curves fits in triangular sector as indicated by the arrow in fragment (a) of Figure 8 that proves results of simulation as consistent to experimental data, although mechanical and aerodynamic parameters of the rock mass at the experimental site was not published by Lidin et al. (1968). These parameters were determined approximately from a handbook as similar to those used during the simulation.

\subsection{GAS FLOW DYNAMICS DURING DRILLING OF THE HOLE}

Lidin et al. (1968) monitored methane outflow from several wells (Fig. 9a). Different rate of gas outflow may be explained by different thickness of the coal seams, variation of wells drilling speed between 5.8 and $13.9 \mathrm{~m} / \mathrm{h}$, and might be not the same content of methane. It should be stressed the experimenters lost quick methane from accounting because essential 


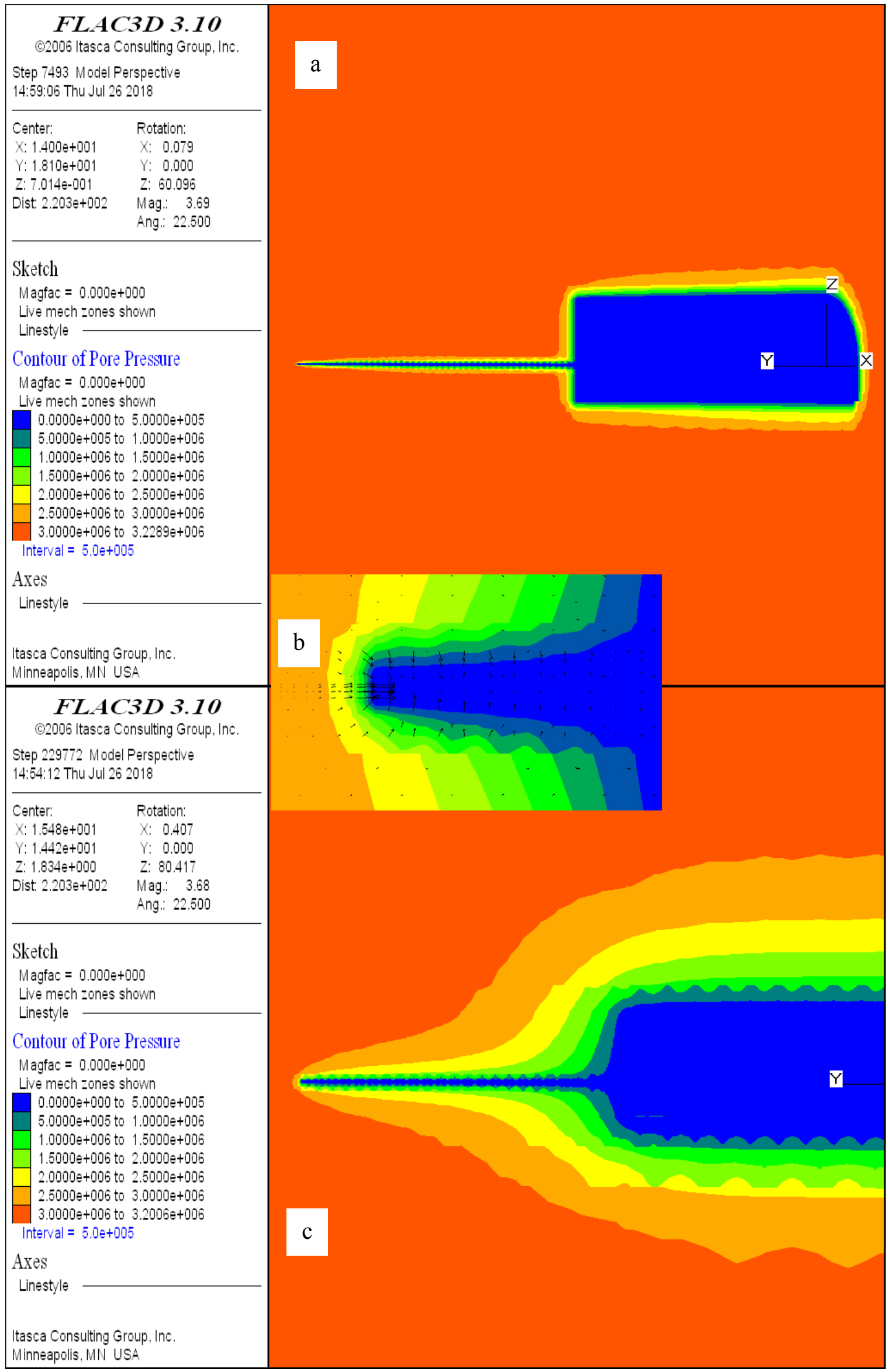

Fig. 7 Gas pressure distribution during ultimately fast driving and drilling (a) and slow (c); (b) - vector's flow around the hole face. 


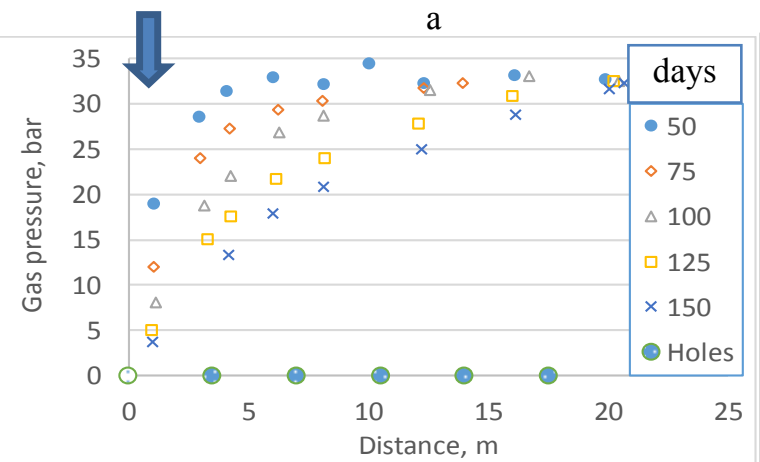

Fig. 8 Gas pressure distribution around a hole according Lidin et al. (1963) (a) and FLAC3D (b)
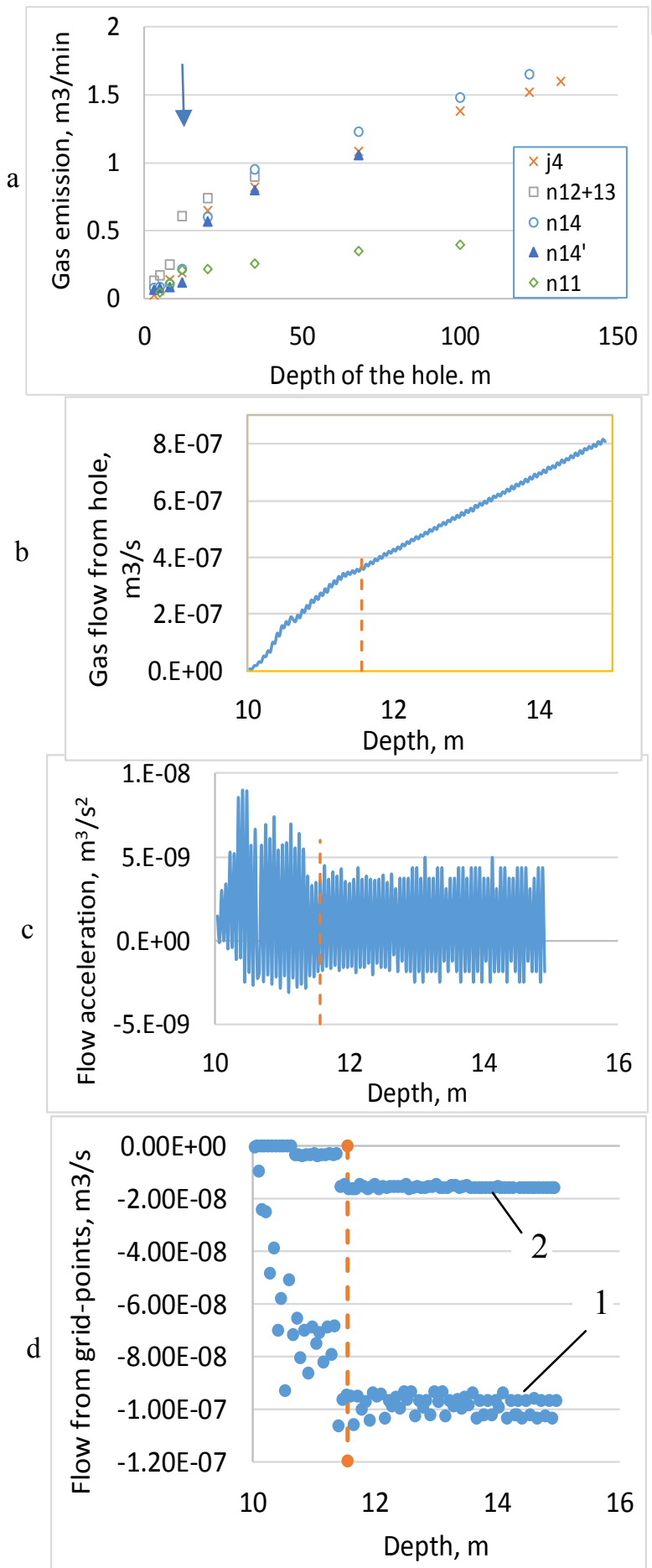

b

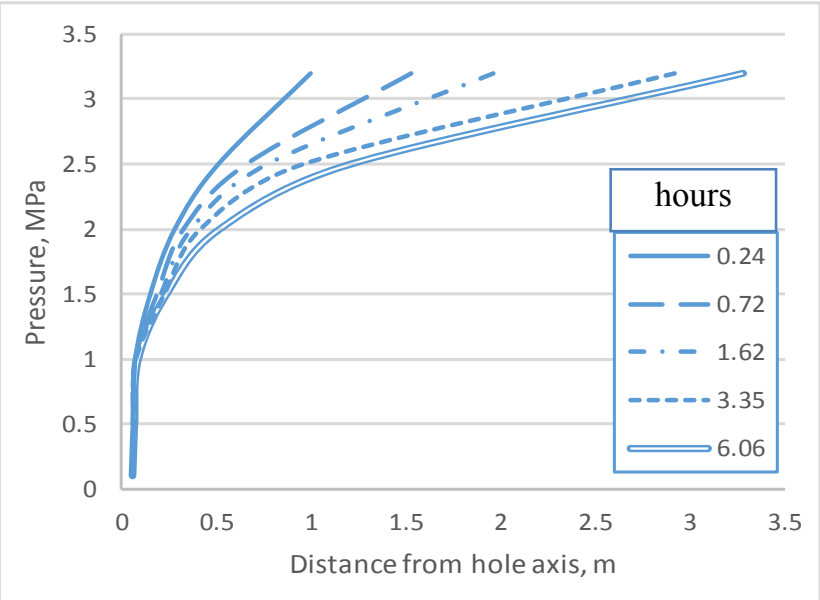

period needs to withdraw drilling instrument from the long wells and install a packer and a flow counter. By all accounts, the experimenters loosed more than $20 \%$ of the desorbed gas.

The experimental data have two essential features. First, two characteristic intervals may be identified where rate of flow acceleration was different. The first interval is in range from 0 to $12 \mathrm{~m}$ (indicated by the arrow) and demonstrates relatively small rate of gas outflow where it didn't exceed 0.23 cubic meter per minute. The second interval was revealing steady grow of the gas outflow as the wells penetrated the coal seam deeper. The experimenters did not explained when the drilling of the wells started, but it is clear from the book that they prepared this experiment deliberately and drilling of the wells started long after the roadway driving. Therefore, the first interval may be identified as a drained zone where methane partially exhausted and its content diminished because of degassing of the rock mass and coal seam around the roadway.

Secondly, experimental points on the second interval may be interpolated by linear function with confidence more than 0.99 , and acceleration of the gas outflow stabilized at the level of $4 \cdot 10^{8} \mathrm{~m}^{3} / \mathrm{s}^{2}$. This is a very important feature because it allows assume that methane content can be determined from the rate of the gas outflow at an interval beyond the drainage zone. Linear shape of the flow dependence on the length of a well provides an opportunity to assess methane content as a quantity that is proportional to flow acceleration other things being equal. This hypothesis has been tested on FLAC3D model. Figure $9 \mathrm{~b}$ demonstrates outflow rate from the $0.04 \mathrm{~m}$ diameter hole drilled with the speed of $2.78 \mathrm{~cm} / \mathrm{s}$ or $10 \mathrm{~m} / \mathrm{h}$, and $9 \mathrm{c}$ shows the acceleration of the flow. Depth of $10 \mathrm{~m}$ in the model corresponded to position of the roadway face or mouth of the hole. Vertical intermitted line indicates boundary of the drained zone in front of the face.

Apparently, the diagram in Figure $9 \mathrm{~b}$ is similar to the experimental diagrams depicted in Figure 9a, and acceleration of the outflow stabilized after

Fig. 9 Gas flow characteristics: (a) outflows from experimental holes (Lidin et al., 1968); (b) - numerically simulated outflow from the hole and its acceleration (c); (d) - outflows from separate grid-points on the hole's face: 1 - from a central point of the hole's face, 2 - from a peripheral point 
crossing the hole over drainage boundary (Fig. 9c) at the level of $3.75 \cdot 10^{-9} \mathrm{~m}^{3} / \mathrm{s}^{2}$. Some fluctuation of the acceleration is a sequence of discrete nature of the model that was divided with finite difference grid. Adjusting the model's hole diameter to the experimental well diameter provides $3.38 \cdot 10^{-9} \mathrm{~m}^{3} / \mathrm{s}^{2}$ that is close to experimental result. However, it should not be over confident because of initial states difference in the experimental measurements losing the quick gas, and simulated results that monitored all methane.

Additional proof depicted in Figure 9d demonstrated stabilization of the total flow from separate grid-points that was moving with the hole's face. This is the most convincing confirmation of outflow linear accumulation during the face advancing. The total flow from the entire hole is integral characteristic, whereas outflows from separate points are local parameters. Being proportional to the hole length, linear grow of the total flow is a result of summation of such elementary sources of the desorbed gas. Notice, maximal stabilized level of total outflow 1 was detected in the points located at the center of the hole face where vectors of the gas flow are maximal (see Fig. 7b), whereas peripheral points emanated amount of gas 2 that is five times less.

Fragment (b) in Figure 10 demonstrates dynamics of flow rate from the central point III of the hole's face that has been located $0.3 \mathrm{~m}$ from the hole's mouth in the drained zone. Fragment (a) shows those points I and II located outside the drainage boundary at the distance 1.6 and $3.4 \mathrm{~m}$ respectively provided essentially higher rate of gas outflow that did not depend on the position of the points and had ultimate constant value, because the hole was penetrating through the fully saturated coal seam.

\subsection{IMPACT OF DRILLING RATE ON GAS FLOW INTENSITY}

The clearest and most visible parameters of gas content are the outflows from separate points of the hole's surface (Fig. 10), but it is impossible to measure them. The gas content can be determined from the rate of total flow from the hole, which can be directly measured using MCSM method described above. Taking derivative of the rate provides parameter that is proportional to the gas content. However, the flow rate is a function not only of the gas content but also depends strongly on the speed of drilling.

Comparison of the flow rates from the $12 \mathrm{~m}$ holes drilled with different speed helped to find how the rate of drilling influences the flow rate (Fig. 11). The rates of drilling were normalized and 1 corresponds approximately to the rate of $1 \mathrm{~km}$ per day. Dependence of the drilling speed on the flow rate is nonlinear, and the most intensive buildup of the flow occurs in the interval of small rates of drilling. Here, the dependence can be described by power function.

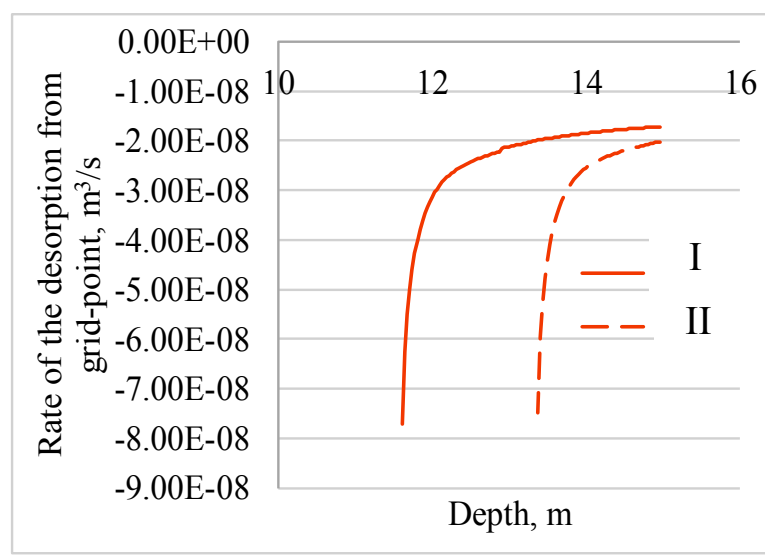

b

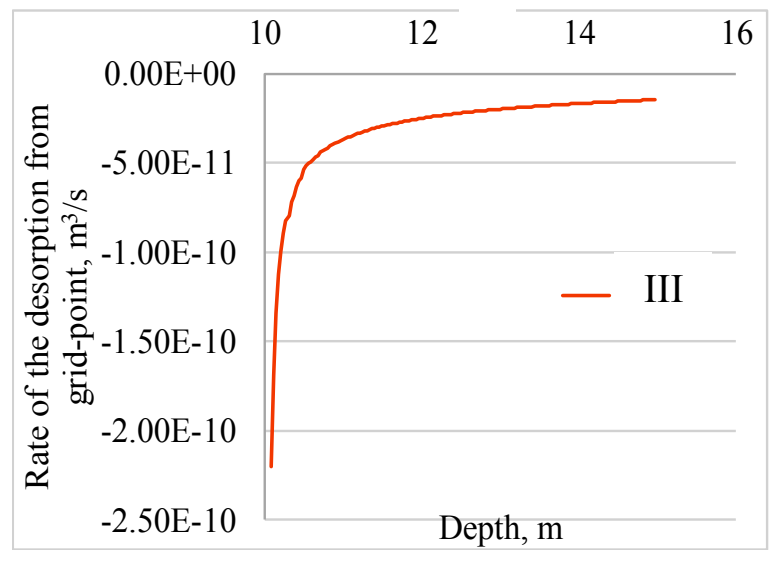

Fig. 10 Gas flow dynamics from separate grid-points.

$w=r^{0.463}$

Where $w$ is a factor of correction, $r$ is the relative speed of drilling: $r=1$ corresponds to $1 \mathrm{~km} /$ day.

This nonlinear dependence has physical explanation. Process of the gas desorption from the coal seam and filtration into a cavity of a drilling hole is nonstationary. Fragments $(\mathrm{a}, \mathrm{b})$ in Figure 10 demonstrate that flows are highly non-equilibrium at initial stage of degassing and total flow is integrating from intensively emanated portions of the quick gas from the leading part of the hole and residual amount that continues to desorb slowly with almost constant rate at the lagging parts of the hole. Share of the residual gas in the total outflow from the hole was declining as the speed of drilling accelerated. Therefore, fast drilling increased contribution of the quick gas and the rate of the total gas flow tended to increase with constant acceleration because increments of the quick gas are the same over the hole's length (Fig. 10b).

A specific temporary increase of the gas flow acceleration occurred during approach of the hole to the boundary of the drained zone (Fig. 9c), as this interval provided maximum gradient of transition from the residual methane in the drained zone to the quick gas outside the zone. 


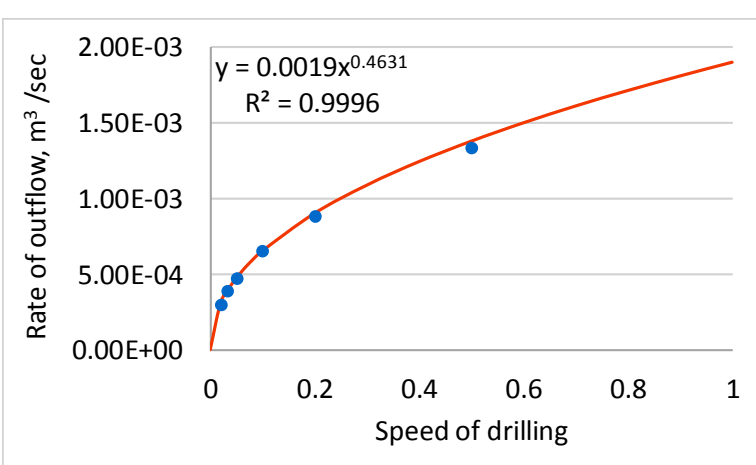

Fig. 11 Effect of drilling speed on rate of methane outflow.

Speed of a hole's drilling may fluctuate in a real underground environment, and corresponding rate of the gas flow should be corrected according to the power function (5). This will help to reveal spatial variation of the gas content, as it may vary at different parts of the rock mass or a coal seam. For example, micro-faults concentrate extra amount of the gas (Alsaab et al., 2009; Boothroyd, 2017) that increases probability of the bursts. Comparison of the measured in different sites results can be made after their correction using formula (5). For example, all measured rates of the flows may be condensed to the maximum speed of drilling reducing additionally to the hole's area of surface. Although it is expedient to reduce different speeds of drilling to those produced the most reliable data or having maximum confidence.

Processing of the results of gas outflow monitoring depends on the concrete aim of exploration. To compare different deposits, coal seams or specific sites and areas, a geologist should condense the measurements to the same speed of drilling and reduce to the same well's diameter. Nitrogen as diluent of coalbed methane will be relevant during drilling exploration with flashing liquid, as nitrogen does not dissolve essentially in water.

Content of coalbed methane will be proportional to acceleration of the outflow:

$x=z \cdot a$

Where $x$ is methane content, $\mathrm{m}^{3} / \mathrm{t}$;

$z$ is proportionality coefficient, $\mathrm{s}^{2} / \mathrm{t}$;

$a$ is methane outflow acceleration, $\mathrm{m}^{3} / \mathrm{s}^{2}$ in standard conditions (standard speed of drilling and bit diameter).

It should be stressed accuracy of the gas content measurement will grow as the diameter of the well and its length (depth) will increase due to the probability of crossing of the representative defects and fractures rises. According to experimental data, preliminary value of $z$ is $2.62 \cdot 10^{8} \mathrm{~s}^{2} / \mathrm{t}$, but special research should be made to determine confident diapason of this coefficient.

The rate of the gas outflow from a hole implicitly contains information concerning both the gas content and its diffusivity. However, explicit statistics of expected time of the coalbed methane recovery may be collected after discontinue of the drilling and monitoring of outflow rate evolution with immovable face of the hole.

Forecast of the bursts should be done using the same standard drilling instrument, especially diameter of the bit. Thus, gas flow acceleration will be the most relevant parameter for determining of the drained zone boundary and assessment of propensity of the gas to a burst. Noticeably, MCSM is the fastest method to detect position of the drained zone frontier and to measure initial rate of the free gas flow from a hole, although monitoring of the desorbed gas flow may last as long as it is necessary. However, the slow and residual gas is much more relevant for extrapolation now, because whole gas including the most intensive free methane as well as initial desorbed portion of slow gas can be reliably monitored by MCSM method. The slow gas flow decays down to zero level in contrast to the quick gas that should be extrapolated to maximal unknown and illusive value that always escapes from investigators using traditional methods of direct measurement.

\subsection{AUTOMATION OF THE MEASUREMENT PROCESS}

MCSM method is easy to operate promptly during drilling of a hole, as it evolves electronic devices that provide good opportunity to automate this process. Figure 12 demonstrates a possible schematic of a system that control process of the measurement.

Timer generates impulses commanding controller that periodically collects the data from flow meter, laser distance meter, and device that monitors concentration of methane. Controller processes input data and corrects them eliminating the lag between injection of the neutral gas and moment of the mixture concentration measurement. Injected neutral gas needs a certain period to travel to the hole's face and return

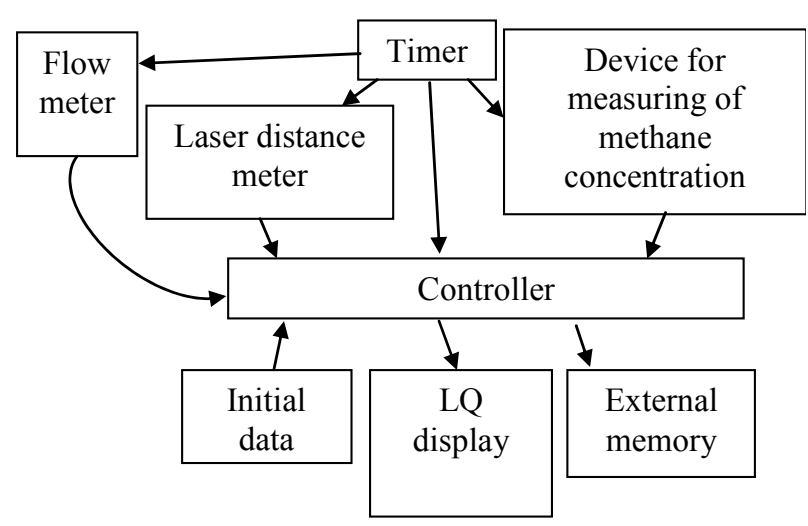

Fig. 12 Schematic of the measurement system automation. 
back to its mouth. Durations of the neutral gas movement back and forth are different because the period of inside trip depends on the channel diameter in the drilling bar whereas the rate of methane outflow regulates the time of return getaway. Thus, depth of the drilling hole should be corrected for the lagging between injection of the neutral gas portion and measurement of corresponding concentration:

$l_{c}=l\left(1-\left(s_{c} / q_{a}+s_{g} / r_{m}\right) r_{d}\right)$

Where:

$l_{c}$ is corrected depth of the hole that corresponds to injected portion of the neutral gas and used during construction of the diagrams like those depicted in Figure 9;

$l$ is the actual current depth of the hole;

$s_{c}$ is area of the channel 8 in the drilling rod (Fig. 1);

$s_{g}$ is area of the gap between the drilling rod and hole's walls;

$q_{a}$ and $r_{m}$ are flows rates of neutral gas and methane neutral gas mixture respectively (volume per time); $r_{d}$ is the speed of hole's drilling (length per time).

Results of processing can be displayed or saved to an external memory. The diagram of the methane outflow acceleration could be the minimum output, which would satisfy both exploration of the gas content and safety consideration for assessment probability of the gas outburst. Diameter of the hole is the most important initial information for reduction of the measurement results to a standard condition.

\section{CONCLUSION}

Existent methods for direct measurement of coalbed methane content have a common flaw that causes lost from 12 to $20 \%$ of unaccounted gas. This paper described a novel MCSM method that monitored all methane synchronously to drilling a hole. Controlled portion of neutral inert gas was injecting into the hole during drilling, while a device monitored methane concentration of the mixture at the hole's mouth. Coalbed methane content has been derived from these data according a simple formula as a function of the gas outflow acceleration. This novel method was successfully tested in a coal mine.

Computer simulation of gas flow using FLAC3D code assisted to investigate of transitive and nonstationary outflow of methane from the hole that was drilling from the face of a driven underground roadway. Process of the gas outflow from an elementary or localized area (a grid point) consists of two stages. The first short stage reflects intensive outflow of so-called quick (free) gas that follows with the second stage of slow emanation of the desorbing gas decaying asymptotically to zero level.

Total outflow of methane from the hole was integrated from the elementary grid-point flows. The rate of the outflow was proportional to the depth of hole's penetration into a coal seam. Giving a constant speed of drilling, acceleration of the gas outflow varied essentially in the range of the drained zone adjacent to the roadway face, but speeding up of the flow rate had stabilized after the hole's face crossed the drained frontier. Thus, invented MCSM method provided two important parameters: position of the zone boundary where methane has been partly drained, and the value of stabilized flow rate acceleration that is proportional to the coalbed methane content outside the drained zone.

MCSM method does not lose any portion of methane from accounting that is important advantage in comparison to known widely adopted methods used for direct measurement of coalbed methane. In addition, MCSM method monitors methane continuously and synchronously to drilling. This cuts the measurement time to the minimum and provides information about the gas from every point of a hole that increases accuracy of the measurement and is of great practical importance. MCSM is the fastest method to detect position of the drained zone frontier and to measure initial rate of the free gas flow from a hole, although monitoring of the desorbed gas flow may last as long as it is necessary.

This innovative technology ideally suits to automation. In this case, characteristics of methane outflow will be recorded automatically during drilling of a hole. Therefore, no extra time needs over drilling period to measure dangerous gas emission that is of great importance from safety considerations. Monitoring of methane emission at certain position of a hole's face using mechanical packer takes from 5 minutes to an hour depending on the depth of a hole. Desorbometric method needs certain period to determine a trend of methane emission rate even if to use automatic desorbometer. This imposes restriction on the distance between adjacent points of a hole where measurements may be done, what essentially reduces reliability of the overall assessment of gas content distribution along the hole. MCSM is the only technology, which naturally takes into consideration non-stationarity of the gas desorption. The other methods stumble and seriously suffer loss of accuracy due to transitive nature of desorption process.

MCSM method can be applied for commercial assessment of coalbed methane recovery and forecast of the dangerous gas bursts during underground, coal extraction.

Combination of the gas flow measurement during hole's drilling and idling may provide additional valuable information. This mode is an object for future investigation. Proportionality factor $z$ between methane outflow acceleration and its content is planned to verify and define more accurately in future works.

\section{ACKNOWLEDGEMENT}

National Academy of Sciences of Ukraine, grant 0117U002193, has supported this work. Assistance of V.V.Petrov is greatly acknowledged during testing of MCSM method in Krasnolimas'ka coalmine. 


\section{REFERENCES}

Ali, A., Alves, T.M., Saad, F.A., Ullah, M., Toqeer, M. and Hussain, M.: 2018, Resource potential of gas reservoirs in South Pakistan and adjacent Indian subcontinent revealed by post-stack inversion techniques. J. Nat. Gas. Sci. Eng., 49, 41-55. DOI: 10.1016/j.jngse.2017.10.010

Alsaab, D., Elie, M., Izart, A., Sachsenhofer, R.F., Privalov, V.A., Suarez-Ruiz, I., Martinez, L. and Panova, E.A.: 2009, Distribution of thermogenic methane in Carboniferous coal seams of the Donets Basin (Ukraine): Applications to exploitation of methane and forecast of mining hazards. Int. J. Coal Geol., 78, 27-37. DOI: 10.1016/j.coal.2008.09.004

Baiquan, T.L. and Yang, L.W.: 2017, Impact of matrixfracture interactions on coal permeability: Model development and analysis. Fuel, 207, 522-532. DOI: 10.1016/j.fuel.2017.06.125

Bertard, C., Bruyet, B. and Gunther, J.: 1970, Determination of desorbable gas concentration of coal (direct method). Int. J. Rock Mech. Min. Sci. 7, 43-65.

Black, D.J.: 2017, Investigations into the identification and control of outburst risk in Australian underground coal mines. Int. J. Min. Sci. Technol., 27, 749-753. DOI:10.1016/j.ijmst.2017.07.006

Boothroyd, I.M., Almond, S., Worrall, F. and Davies, R.J.: 2017, Assessing the fugitive emission of $\mathrm{CH} 4 \mathrm{via}$ migration along fault zones - Comparing potential shale gas basins to non-shale basins in the UK. Sci. Total Environment, 580, 412-424. DOI: $10.1016 /$ j.scitotenv.2016.09.052

Cheng, L. Shugang, L. and Shouguo, Y.: 2018, Gas emission quantity prediction and drainage technology of steeply inclined and extremely thick coal seams. Int. J. Min. Sci. Technol., 28, 415-422. DOI: $10.1016 /$ j.ijmst.2017.12.020

Diamond, W. P. and Levine, J. R.: 1981, Direct method determination of the gas content of coal: Procedures and results. US Bur. Mines, Rep. Invest. 8515.

Guiyang, Y., Gang, W., Lin, X., Wenzhou, D. and Qiming, H.: 2017, Direct fitting measurement of gas content in coalbed and selection of reasonable sampling time. Int. J. Min. Sci. Technol., 27, 299-305.

DOI: $10.1016 /$ j.ijmst.2017.01.016

Itasca Consulting Group, Inc.: 2008, FLAC3D - Fast Lagrangian Analysis of Continua in 3 Dimensions, Ver. 4.0. User's Manual, Minneapolis, Itasca.

Jiang, J. and Yang, J.: 2018, Coupled fluid flow and geomechanics modeling of stress-sensitive production behavior in fractured shale gas reservoirs. Int. J. Rock Mech. Min. Sci., 101, 1-12. DOI: 10.1016/j.ijrmms.2017.11.003

Kim, A.G.: 1977, Estimating methane content of bituminous coalbeds from adsorption data. US Bur. Mines, Rep. Invest., 8245.

Kissell, F.N., McCulloch, C.M. and Elder, C.H.: 1973, The direct method of determining methane content of coalbeds for ventilation design. US Bur. Mines, 7767.

Konečný, P. and Kožušníková, A.: 2016, Characterizing gas permeability and pore properties of Czech granitic rocks. Acta Geodyn. Geomater., 13, 4, 331-338. DOI: $10.13168 /$ AGG.2016.0015

Levine, J.R.: 1992, Oversimplifications can lead to faulty coalbed gas reservoir analysis. Oil Gas J., 23, 63-69.

Lidin, G.D., Airuni, A.T., Bessonov, U.A. and Smirnov, N.S.: 1968, Investigation of degassing processes in extracted, undermined, and overmined coal seams. Moscow, Institute for Physics of the Earth.

Liu, M. and Mitri, H.: 2007, Coal and gas outburst in a coal mine shaft development: A case study. 26th
International Conference on Ground Control in Mining, 348-352.

Liu, S. and Harpalani, S.: 2013, Permeability prediction of coalbed methane reservoirs during primary depletion. Int. J. Coal Geol., 113, 1-10. DOI: 10.1016/j.coal.2013.03.010

Mullen, M.J.: 1989, Coalbed methane resource evaluation from wireline logs in the northeastern San Juan basin: A case study. Proc. 1989 Coalbed Methane Symp., University of Alabama, Tuscaloosa, AL, 167-184.

Nazimko, V.V. and Roy, A.V.: 2018, Patent of Ukraine, No. 115,962. Bulletin, 2, Kyiv, Institute of Intellectual Ownership.

Nazimko, V.V. and Babenko. K.V.: 2011, Use of FLAC3D for mining induced seismicity prediction. Continuum and Distinct Element Numerical Modeling in GeoEngineering, Sainsbury, D., Hart, R., Detournay, C. and Nelson, M. (eds.) Paper: 02-07.

Owen, L.B. and Sharer, J.: 1992, Method calculates gas content per foot of coalbed methane pressure core. Oil Gas J., 2, 47-49.

Regulations for underground mining operations in coal seams that are prone to gas bursts, 2005, SOU 10.1.00174088.011-2005. Kyiv.

Rightmire, C.T.: 1984, Coalbed Methane Resource. Rightmire, C.T., Eddy, G. and Kim, J., (Eds.), American Association of Petroleum Geologists, Studies in Geology, Series 17, 1-15.

Ryan, B.D.: 1994, Coalbed methane canister desorption techniques. British Columbia Geological Survey, Geological Fieldwork 1993, Paper 1994-1, 245-256.

Saghafi, A.: 2017, Discussion on determination of gas content of coal and uncertainties of measurement. Int. J. Min. Sci. Technol., 27, 741-748. DOI: $10.1016 /$ j.ijmst.2017.07.024

Standards Association of Australia, 1991. Australian Standard AS 3980: Guide to the determination of desorbable gas content of coal seams - direct method. North Sydney, NSW.

Szabó, N.P. and Dobrók, M.: 2013, Extending the application of a shale volume estimation formula derived from factor analysis of wireline logging data. Math. Geosci., 45, 837-850. DOI $10.1007 / \mathrm{s} 11004-013-9449-2$

Szlązak, N. and Korzec, M.: 2016, Method for determining the coalbed methane content with determination the uncertainty of measurements. Arch. Min. Sci., 61, 443-456. DOI: 10.1515/amsc-2016-0032

World Energy Resources: 2016, Coal. World Energy Council.

https://www.worldenergy.org/data/resources/resource/coal/

Zhang, C.-L.: 2016, The stress-strain-permeability behaviour of clay rock during damage and recompaction. J. Rock Mech. Geotech. Eng., 8, 16-26. DOI: 10.1016/j.jrmge.2015.10.001

Zhang, J., Xu, K., Wang, B. and Wang, Y.: 2016, Extraordinarily serious gas explosion accidents in coal mines analysis of causes and research on management mode. CSSJ, 26 (2), 73-78.

Zhang, S., Liu, L., Wei, M. and Elsworth, D.: 2018, Coal permeability maps under the influence of multiple coupled processes. Int. J. Coal Geol., 187, 71-82. DOI: $10.1016 /$ j.coal.2018.01.005

Zheng, C., Chen, Z., Kizil, M., Aminossadati, S., Zou, Q. and Gao, P.: 2016, Characterization of mechanics and flow fields around in-seam methane gas drainage borehole for preventing ventilation air leakage: A case study. Int. J. Coal Geol., 162, 123-138. DOI: $10.1016 /$ j.coal.2016.06.008 